\title{
Instructional Quality and Attitudes toward Mathematics: Do Self-Concept and Interest Differ across Students' Patterns of Perceived Instructional Quality in Mathematics Classrooms?
}

\author{
Rebecca Lazarides and Angela Ittel \\ Department of Educational Psychology, Institute of Education, Berlin Institute of Technology, Franklinstraße 28/29, \\ 10587 Berlin, Germany \\ Correspondence should be addressed to Rebecca Lazarides, rebecca.lazarides@tu-berlin.de
}

Received 19 May 2012; Accepted 9 October 2012

Academic Editor: Helga Krinzinger

Copyright ( $) 2012$ R. Lazarides and A. Ittel. This is an open access article distributed under the Creative Commons Attribution License, which permits unrestricted use, distribution, and reproduction in any medium, provided the original work is properly cited.

Using a person-centered research approach, the present study explored individual differences in students' perceptions of instructional quality in secondary school mathematics classes and their relations to students' self-concept and interest in mathematics. Drawing on data collected from 425 high school students from ten schools in Berlin, Germany (male: $53.2 \%$; female: $46.3 \%$ ), latent class analyses (LCA) revealed four distinct patterns of perceived quality of instruction. Almost half of the sample $(46 \%)$ had a high likelihood of perceiving an overall low quality in mathematics classes. Those students reported particular low self-concept and interest in mathematics. Compared to male students, female students were significantly more likely to belong to this "challenging pattern." Consequences for educational practice are discussed and suggest that instruction in mathematics should take into account learners' highly individual ways of perceiving and evaluating their learning environment.

\section{Introduction}

After major international large scale assessments on educational performance such as the Programme for International Student Assessment (PISA) revealed low to average performance of German students in mathematics and science compared to other participating countries, the enhancement of learning success and later professional careers in the STEM-disciplines (STEM = science, technology, engineering, and mathematics) have been prioritized in educational policy $[1,2]$. Attitudinal and affective variables such as mathematics self-concept and interest were shown to be central to students' achievement in mathematics [3]. Mathematics self-concept, which is broadly defined as a persons' selfrelated perceptions in the area of mathematics that are formed through experience with others and one's own interpretations of their environment [4], is reciprocally related to achievement in mathematics and positively related to course choice in mathematics domains during uppersecondary education $[5,6]$. Another key factor for students' learning is students' interest in mathematics, which is shown to be related to achievement goals in mathematics classes and mathematics-related career choices $[7,8]$. Students who are interested in mathematics enjoy engaging in math, tend to reengage in mathematical contents, and view mathematics as important for their individual development [9].

Both self-concept and interest in mathematics are influenced by educational settings and teaching styles. Research suggests that particular aspects of instructional quality in mathematics classrooms such as classroom management, classroom climate, and cognitive activation relate to students' attitudes and emotions concerning mathematics [1012]. Although a vast number of previous studies consider characteristics of instruction and their impact on learning [13-16], individual differences in students' perceptions of instructional quality in their mathematics classrooms are explored less frequently. However, it is important to address individual differences as students' learning success depends highly on the level of adaptability of learning environments to students' individual needs $[17,18]$. Subsequently, in 
the current study, we explored distinct student patterns of perceived instructional quality in mathematics classes. Thereby, the aim of this research was to analyze whether students' self-concept and interest in math differ across distinct student patterns. As empirical studies suggest that demographic variables such as age and gender are related to students' perceptions of instructional quality in mathematics classrooms $[19,20]$, we considered in our analysis associations between these demographic characteristics and students' patterns of perceived instructional quality.

\section{Characteristics of Instructional Quality Mathematics Self-Concept and Interest}

Referring to a cognitive perspective of learning, research on instructional quality conceptualizes learning as a selfdetermined, constructive, and self-regulated process of conceptual growth, which is supported or undermined by perceived learning conditions and shaped by a dynamic interplay among personal, behavioral, and environmental factors [21-23]. Thus, a high level of instructional quality of learning environments is seen as a prerequisite to enhanced learning outcomes depending on students' subjective perceptions, preknowledge, and internal structures of cognitive processing $[24,25]$. Based on related theoretical frameworks such as self-determination theory (SDT; [26]), research concerning relations between learning environments and students' motivation often focuses on students' individual perceptions of their learning environment [13, 27, 28]. SDT suggests that learning conditions that lead to the fulfillment of students' basic psychological needs for autonomy, competence, and social relatedness facilitate students' intrinsic motivation. Thus, related research highlights students' individual experiences in their learning environments. Conversely, research on effective teaching strategies often considers students' perceptions aggregated on class level [16, 29]. Using aggregate measures of classroom context refers to instructional quality as an objective criterion of the learning environment that is perceived by all students within one class in a similar way [30]. However, it highly depends on the aims of research as to which conceptualization of instructional quality is most appropriate. Lütdke et al. [31] point out that assessing characteristics of learning environments with data aggregated at the group level focuses on differences between learning environments, while assessing students' personal perceptions focuses on differences between students. Concerning motivational learning outcomes, it is unclear which conceptualization is most appropriate. Clausen [32] highlights that students' perceptions aggregated at the class level are valid indicators of teaching behaviours and are highly related to students' motivational learning outcomes. However, Kunter et al. [30] highlighted that the validity of mean ratings as descriptions of the learning environment might be questioned. Their results indicated that mean ratings of classroom management strategies were unrelated to the change in students' interest in mathematics from grade 7 to grade 8 , while individual perceptions of classroom features were highly related to students' change in interest. Referring to this theoretical and empirical work, the present study aimed to examine how students' individually experience the instructional quality in their classrooms. To this end, we questioned which subtypes of individual perceptions of instructional quality exist, how gender and age are related to potential subtypes, and how the subtypes differ in terms of motivational and attitudinal learning outcomes. Thus, we focused on students' individual perceptions rather than on data aggregated at the class level. Appropriate to the aims of the present study, person-centered research approaches such as Latent Class Analysis (LCA) allow the distinction of specific homogenous subgroups of students within a heterogeneous total population of students [33].

Regarding the question of how instructional quality is defined, three basic dimensions which structure the array of single characteristics of teaching and classroom components have emerged consistently as being crucial for motivational learning outcomes in mathematics [12, 34, 35]. Although the terminology used varies [36], the three basic dimensions are (1) classroom management, (2) supportive climate, and (3) cognitive activation. Our study enlists single characteristics of instruction assigned to these three dimensions as indicators of instructional quality in mathematics classes.

The basic dimension of classroom management typically refers to an efficient classroom and time management or low levels of disruptive student behavior [36, 37]. Recent empirical studies furthermore outline high levels of clarity and structuredness of teachers' instruction as important components of an effective classroom management [12, 38]. An efficient classroom management characterized by high structuredness and clarity of instruction is a salient predictor of students' interest in mathematics classes [16]. Theoretically, research related to self-determination theory [26] revealed that effective classroom management enhances students' experience of intrinsic need satisfaction and thus facilitates students' interest $[28,30,39]$.

The basic dimension of supportive climate includes features of teacher-student interaction such as supportive teacher-student relationships, caring and attentive teacher behavior, or constructive feedback [18]. Based on social comparison theory [40], research has shown that students' selfconcepts are highly influenced by their social environment and the social comparisons provided by this environment [41]. Langford et al. [42] point out, for example, that perceived social support leads to more accurate perceptions of normative peers [43]. Sarason and colleagues [43] propose that low-perceived social support may encourage downward social comparisons. Perceived social support further leads to the experience of relatedness to others, whereby facilitating students' intrinsic motivation $[39,44]$. Thus, studies show that the degree to which students' perceive teacher support in class plays a critical role in the development of students' self-concept and interest in mathematics $[13,14]$.

The basic dimension of cognitive activation refers to characteristics of instruction, which promote students' conceptual understanding by including, for example, challenging tasks or enhancing different solution strategies and nonroutine problem solving [17]. Additionally, discursive 
effectiveness, which refers to students' opportunity to coconstruct knowledge by participating in mathematics classroom discourse, is viewed as a mechanism to activate cognitive processing $[18,45]$. Participating in cognitively challenging classroom discourse facilitates students' emotional well-being [46] and thus is linked to students' interest in mathematics classrooms [15] and students' mathematics self-concept [47].

Concerning the relation between perceived characteristics of instructional quality in math and science classes and motivational learning outcomes, Eccles and colleagues [20] suggest in their stage-environment-fit approach that the consistent developmental decline of attitudinal and motivational-affective learning outcomes during junior high school $[10,16,48]$ results from a mismatch between the needs of developing adolescents and the opportunities afforded to them by their learning environments. However, research has shown that distinct subtypes of students exist despite this general decline, ranging from students with overall positive characteristics (e.g., high self-concept of ability and interest) to students with "challenging" characteristics (e.g., low self-concept of ability and interest) [49]. Seidel [49] reveals that the differences in students' motivational learning outcomes relate to perceived learning conditions in mathematics classrooms such as instructional clarity and interaction with the teacher. Based on a theoretical conceptualization of learning as a self-directed process, in which teachers provide learning opportunities that must be perceived and utilized by students $[17,50]$, in the present study we expected to find distinct student subtypes with respect to perceived instructional quality corresponding to the subtypes of motivational learning outcomes as shown by Seidel [49]. Thus, we expected to find a subtype of learners with overall positive perceptions of the characteristics of instructional quality in math class. We expected further to find another extreme subtype of students with overall negative perceptions of the instructional quality in math class. As it is well known that single characteristics of instructional quality, such as perceived structuredness and autonomy support, are independent learning factors that can be complementary [51], we expected to find mixed subtypes of students' perceived characteristics of instructional quality structuredness of teachers' instruction, teachers' social support, and discursive effectiveness.

In the present study, we controlled for gender and age effects in the latent-class models. Previous studies revealed that gender has been shown to be related to learning environment perceptions [52] as well as to mathematics self-concept and interest [10, 53]. Ditton [19], for example, showed that male students evaluate their mathematics teachers' performance more positively than their female classmates. Furthermore, age was shown to be related to students' perceptions of the instructional quality in mathematics classes. Eccles and colleagues [20] suggest that negative learningrelated changes in adolescence as in, for example, the decline of students' self-competence beliefs and interest in math and science $[54,55]$ results from an increasing mismatch between adolescent students' needs and the opportunities afforded to them by their classrooms. Referring to these results, the present study tested for relations between gender and age and students' pattern of perceived quality of instruction in mathematics classes. Instructional quality and attitudinal and affective variables were assessed using student self-report scales. Compared to objective descriptions of instructional quality, student ratings offers a range of conceptual advantages such as a high reliability due to students' extensive experiences with different teachers and experiences with the same teacher in different domains [31]. However, in particular, students' subjective perceptions of their learning environment were shown to be highly predictive for motivational learning outcomes [30]. In her multilevel study, Daniels [16] revealed that students' perceived structuredness in mathematics classrooms influences mathematics interest at the individual and class level. However, the effect was considerably stronger at the individual level. Frenzel et al. [29] conclude from their data that the relationships between perceived quality of instruction in mathematics classrooms and students' emotional experiences in class predominantly function at the individual level and not at the level of averaged classroom experiences. Although a large volume of research examines the relations between instructional quality and factors of students' learning, nearly no empirical studies focus on students' distinct patterns of perceived instructional quality as rated by students themselves. Referring to the high importance of students' subjective experiences in their learning environments for successful learning processes [16, $29,30]$ there is an urgent need for explorative studies on students' individual patterns of perceived instructional quality and their associations to students' learning.

\section{Research Questions}

Based on the theoretical state of research and previous empirical results, the present study addressed the following explorative research questions.

(a) What distinct student patterns can be identified with respect to perceived levels of characteristics of instructional quality (structuredness, teachers' social support, and discursive effectiveness) in secondary school mathematics classes?

(b) How do the demographic characteristics gender and age relate to patterns of instructional quality in math?

(c) Do the attitudinal and affective variables mathematics self-concept and interest differ significantly across the distinct patterns of instructional quality in mathematics classes?

\section{Method}

4.1. Participants and Procedure. The sample included 425 high school students (grades 8 through 10) from 21 classrooms from ten schools in Berlin, Germany. Each classroom had a different teacher. The mean age of the participating male $(53.2 \%)$ and female $(46.3 \%)$ students was 14.93 years ( $\mathrm{SD}=1.04$; age range: $13-17)$. The majority of participants $(54.6 \%, n=232)$ reported that they and both of their parents 
were born in Germany. Students' participation was voluntary and required parental consent if students were under 14 years old, following the research principles of the Berlin Senate Administration for Education, Science and Research. The recruitment procedure consisted of sending letters addressed to the students and their parents explaining the aims and procedure of the study and requested students' participation. Trained research assistants introduced the students to the questionnaire, which they completed in approximately 45 minutes during their mathematics class.

4.2. Measures. All items assessing instructional quality, described in more detail below, were divided into binary items to indicate those students' with low to moderate ratings on the perceived instructional quality characteristics versus those children with high ratings. After examining the factor structure using confirmatory factor analysis, items with high loadings on the three factors "structuredness," "social support", and "discursive effectiveness" (<.75) were used as indicators for Latent Class Models.

4.2.1. Structuredness. The scale for "structuredness" assessed the extent to which students perceived their teachers' instructions in mathematics class as well structured. Thus, the study focused on structuredness in terms of "a systematic approach in the design of instruction" [56, page 252]. Perceived structuredness was measured with a 4 -item scale derived from Daniels [16] (e.g., "Our teacher in mathematics usually summarizes everything, helping us remembering what we learned in class.") The 4-point Likert scale ranging from 1 (strongly disagree) to 4 (strongly agree) yielded good internal consistency with Cronbachs' $\alpha=.85$.

4.2.2. Social Support. The participants' sense of their mathematics teachers' social support was measured using a 4-item scale by Daniels [16]. An example item is "Our mathematics teacher makes time for students who want to talk with him/her." The 4-point Likert scale ranging from 1 (strongly disagree) to 4 (strongly agree) demonstrated adequate internal consistency with Cronbachs' $\alpha=.79$.

4.2.3. Discursive Effectiveness. Students' perception of opportunities to participate in decisions concerning their learning process in mathematics was assessed with the 7-item scale "Feeling of discursive effectiveness" from Steinert et al. [57]. An example item is "Students' opportunities to decide things in class are never seriously considered by our mathematics teacher." Using a 4-point Likert response scale, items ranged from 1 (strongly disagree) to 4 (strongly agree). All items from the scale were negatively worded and recoded so that a higher score indicated greater discursive effectiveness. The scale demonstrated good internal consistency with Cronbachs' $\alpha=.83$.

4.2.4. Students' Interest in Mathematics Class. Students' interest in mathematics class was measured with a 9-item self-report scale, based on Berger [58]. An example item is "I value mathematics class particularly because of the interesting topics." The 5-point Likert-type scale ranged from 1 (strongly disagree) to 5 (strongly agree). The scale displayed good internal consistency with Cronbachs' $\alpha=.83$.

4.2.5. Self-Concept in Math Class. Students' self-concept in mathematics class was measured using an established German 4-item self-report scale derived from Bos et al. [59]. An example item is "I' $\mathrm{m}$ just not good at math." The 4-point Likert scale ranging from 1 (strongly agree) to 4 (strongly disagree) was recoded so that a higher score indicated greater self-concept in math class. The scale yielded good internal consistency with Cronbachs' $\alpha=0.81$.

4.3. Data Analysis. All analyses were conducted using Mplus Version 6.12 [60]. Due to the cluster sampling of the data (students' in classrooms), and thus the nonindependence of observations, corrections to the standard errors and chisquare test of model fit were obtained using a maximum likelihood estimator with robust standard errors for all steps in data analysis (Type $=$ Complex [60]).

Steps in Data Analysis.

(1) Separate confirmatory factor analyses (CFAs) were conducted for the 16 items of the self-report scales structuredness, social support, and discursive effectiveness, which were used as indicators for the latent class analysis to examine the adequacy of the factor structure and to identify problematic items (low loadings; cross-loadings).

(2) A series of latent class analysis procedures were conducted. The first step was to choose the optimal number of classes by specifying separate LCA models with various numbers of classes. The appropriate number of latent classes was evaluated based on a comparison between several statistical criteria, including Akaike information criterion (AIC: lowest) [61], Bayesian information criterion (BIC: lowest) [62], sample-size-adjusted Bayesian information criterion (ABIC: lowest), entropy (>.80) [63], and adjusted Lo-Mendell-Rubin Likelihood Ratio Test (LMR LRT: $P$ value is used to determine if the null $k$ 1 class model should be rejected in favor of the $k$ class model). Suggested by a recent simulation study, we gave the most weight to model with the lowest BIC, as BIC value may provide the most reliable indicator of true number of classes [64].

(3) As the current study explored whether gender and age were significantly associated with students' latent class membership, these demographic characteristics were included as covariates in the basic model via multinomial logistic regression.

(4) Mean differences of students' self-reported motivational and cognitive learning outcomes across the latent classes were tested by incorporating the continuous distal outcome variables students' selfconcept and interest in mathematics class into the latent class model with covariates. 


\section{Results}

5.1. Confirmatory Factor Analysis. Based on the established measures, the 16 items of the three self-report scales structuredness, social support, and discursive effectiveness were dichotomized and assigned to three dimensions. After examining this initial model, we identified two items with multiple factor loadings greater than 0.3 and subsequently removed them from the model. The removed items consisted of one item from the social support scale ("Our math teacher usually helps us like a friend."; $M=2.56, \mathrm{SD}=0.90$; standardized loading on latent factor "social support" $\lambda=$ 1.20 and on latent factor "discursive effectiveness" $\lambda=-.52$ ) and one item from the discursive effectiveness scale ("My mathematics teacher often does not listen to what I say.", $M=2.00, \mathrm{SD}=0.84$; standardized loading on latent factor "structuredness" $\lambda=.36$ and on latent factor "discursive effectiveness" $\lambda=.47$ ). Furthermore, due to low loadings compared to the other items which were all greater than .80 , two items were removed from the model ("Our math teacher often says 'We have to' which means 'You have to.", $M=2.33$, $\mathrm{SD}=.96$, and $\lambda=.63$; "In the end in our classroom it depends on who is in charge.", $M=2.13$, SD $=.98$, and $\lambda=.72$ ). The final model with the remaining 12 items fit the data well, $\chi^{2}(51)=63.99, P>.05$; CFI $=.990$; TLI $=.987$; RMSEA $=.02,90 \%$ CI [.00-.02].

5.2. Latent Class Analysis. Although the 5-class model had the lowest AIC- and aBIC-value, results of Nylund et al. [64] reveal that the AIC-value is not a good indicator for class enumeration for LCA models with categorical outcomes. Further, the authors propose that the BIC value more consistently identifies the correct model over the adjusted BIC. Thus, Nylund and colleagues [64] conclude that the $\mathrm{BIC}$ is the most reliable information criterion (IC) between AIC and aBIC information criteria for correctly identifying the number of classes in LCA-modeling. In our model, the LMR LRT test statistics showed the first nonsignificant $P$ value for the 3 -class model, suggesting that the 2 -class model should not be rejected in favor of the 3-class model. However, Nylund and colleagues [64] also emphasize based on results of their Monte Carlo simulation study that the LMR LRT test has inflated Type I error rates for LCA models with categorical outcomes. Thus in our study, we preferred the BIC value as an indicator of the best model fit. As indicated by the lowest BIC-value, the four-class model had the best model fit. Model fit indices for the various latent class models are shown in Table 1. Figure 1 depicts the class profiles. The $y$-axis indicates the probability of a student rating high on the specific instructional quality items, which are listed on the $x$-axis. Latent Classes were labeled referring to their most decisive criterion concerning students' ratings on characteristics of instructional quality. Class 1 was best characterized as the "High Quality Pattern" $(9.8 \%)$ given that students in this subgroup had moderate to high probabilities of reporting high levels of structuredness (.57-.81), high levels of social support by their teacher (.62$.78)$, and high levels of discursive effectiveness (.68-.86) in their mathematics classes. Class 2 was labeled as "High
Structuredness Pattern" (21.9\%) and consisted of students who had high probabilities of reporting high to moderate levels of structuredness of instruction in their mathematics classes (.45-.72), moderate to low probabilities of reporting high levels of social support by their mathematics teacher (.22-.43), and low probabilities of reporting high levels of opportunities in their mathematics classes (.00-.17). Class 3 was denoted as "High Social Support Pattern," as members of this subgroup (22.4\%) displayed, aside from item "social support 4" (.18), overall moderate to high probabilities of feeling supported by their mathematics teachers (.45-.59), low probabilities of reporting high levels of structuredness (.06-.13), and moderate probabilities of reporting high levels of discursive effectiveness (.23-.43). Class 4 was the most prevalent class (45.9\%) and was characterized as "Low Quality Pattern" as students in this subgroup had low probabilities of reporting high levels of structuredness (.00$.04)$, high levels of social support by their mathematics teacher (.00-.05), and high levels of discursive effectiveness (.00-.08) in their mathematics classes.

In a next step, we tested to which extent the groups corresponded to individual classrooms/teachers. We thereby focused only on both extreme patterns as they can be seen as a struggling group "Low Quality Pattern" and a no-risk group "High Quality Pattern". Results of crosstab analysis revealed significant associations between students' group membership and individual classrooms/teachers [Pearson $\chi^{2}=169.83, \mathrm{df}=60$, and $P<.000$; Cramer's $\left.V=0.37\right]$. Multinominal logistic regressions were conducted using dummy-coded classrooms/teachers as independent variables and latent class membership as dependent variable. Class 4 "Low Quality Pattern" was set as reference class. Results revealed that students who were in classrooms numbers 3 , $4,5,15$, and 19 were significantly more likely to belong to the "High Quality Pattern" than to belong to the "Low Quality Pattern" $\left(\mathrm{OR}_{3}=4.68, P<.001 ; \mathrm{OR}_{4}=2.16, P<.01\right.$; $\mathrm{OR}_{5}=8.69, P<.001 ; \mathrm{OR}_{15}=5.59, P<.05 ; \mathrm{OR}_{19}=$ 12.94, $P<.001)$. Using Class 1 "High Quality Pattern" as the reference class, results indicated that students from classrooms numbers 3, 4, 5, 15, and 19 were significantly less likely to belong to the "Low Quality Pattern" than to the "High Quality Pattern" $\left(\mathrm{OR}_{3}=0.21, P<.001 ; \mathrm{OR}_{4}=0.46\right.$, $P<.01 ; \mathrm{OR}_{5}=0.12, P<.001 ; \mathrm{OR}_{15}=0.18, P<.05 ;$ $\left.\mathrm{OR}_{19}=0.08, P<.001\right)$.

5.3. Latent Class Analysis with Covariates. The current study explored whether the demographic characteristics gender and age were associated with class membership by incorporating these variables as covariates in the latent class models. Latent class analysis with covariates is analogous to a multinomial logistic regression approach with latent class membership serving as categorical dependent variable and using observed covariates as independent variables [60]. Class 4 "Low Quality Pattern" was set as the reference group. The model fit statistics of the LCA models with demographic covariates are reported in Table 2. Covariates included gender ( 0 = male; 1 = female; male as referent) and age (centered). In the four-class model with covariates, it was shown that 


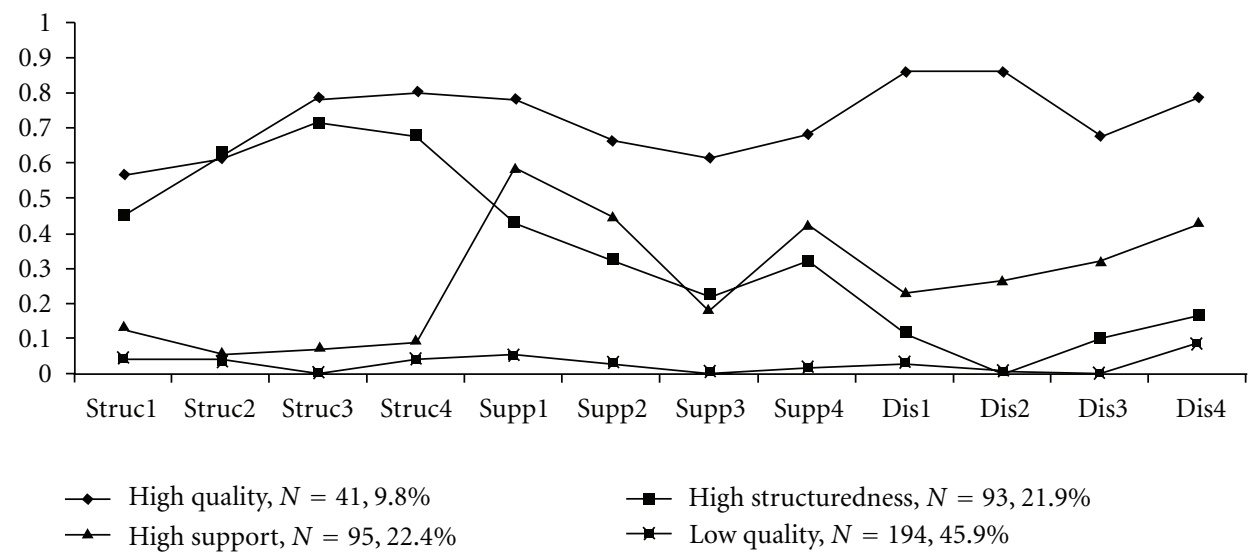

FigURE 1: Latent class characteristics and prevalence for the four-class model.

TABLE 1: Model fit indices for 2-5 class solutions of students' perceived characteristics of instructional quality with and without covariates (gender and age).

\begin{tabular}{|c|c|c|c|c|c|c|c|c|}
\hline \multirow{2}{*}{ Number of classes } & \multicolumn{4}{|c|}{ Without covariates } & \multicolumn{4}{|c|}{ With covariates } \\
\hline & 2 & 3 & 4 & 5 & 2 & 3 & 4 & 5 \\
\hline AIC & 4526.28 & 4392.59 & 4320.60 & 4278.15 & 4505.44 & 4372.51 & 4298.91 & 4260.15 \\
\hline $\mathrm{BIC}$ & 4627.47 & 4546.39 & 4527.02 & 4537.18 & 4618.70 & 4546.44 & 4533.52 & 4555.44 \\
\hline $\mathrm{ABIC}$ & 4548.13 & 4425.81 & 4365.17 & 4334.09 & 4529.84 & 4409.99 & 4349.46 & 4323.78 \\
\hline Entropy & 0.827 & 0.850 & 0.822 & 0.847 & 0.826 & 0.848 & 0.830 & 0.852 \\
\hline aLMR & 0.024 & 0.379 & 0.365 & 0.729 & 0.040 & 1.000 & 1.000 & 1.000 \\
\hline
\end{tabular}

Note. AIC: Akaike's information criteria. BIC: Bayesian information criteria. ABIC: sample-size-adjusted Bayesian information criterion. aLMR LRT: LoMendell-Rubin adjusted likelihood ratio test.

partial measurement noninvariance needed to be considered. Gender directly influenced the probability to rate high on the item "social support 1 " $(\mathrm{OR}=0.51 ; \beta=-.668$, $\mathrm{SE}=.257, z=-2.59$, and $P<.01)$. That is, compared to male students, female students were significantly less likely to endorse the item "Our math teacher always has time to speak with his students." Concerning the associations between demographic characteristics and latent class membership, the results of the four-class model demonstrated that age had no significant effect at all. Gender was significantly associated with students' membership in Class 1 "High Quality Pattern". Results demonstrated that the odds of belonging to the "High Quality Pattern" for females were only 0.45 as high as for males $(\mathrm{OR}=0.45 ; \beta=-.801, \mathrm{SE}=.387, z=-2.07$, and $P<.05)$. Using an alternative parameterization for the categorical latent variable regression with Class 1 "High Quality Pattern" as reference class, it was shown that the chance of belonging to Class 4 "Low Quality Pattern" for female students was twice as high as for male students $(\mathrm{OR}=$ 2.74; $\beta=1.006, \mathrm{SE}=.364, z=2.77$, and $P<.01$ ). Age did not relate significantly to students' pattern of perceived instructional quality.

As shown in preliminary classroom-related analysis, particular classrooms were significantly related to students' group membership in the perceived "High Quality" and perceived "Low Quality" groups. Therefore, examining the question whether female students possibly were on average more likely to attend classrooms which were significantly related to the perceived "Low Quality Pattern," we examined the associations between those classrooms numbers 3, 4, 5, 15 , and 19 and gender via crosstab analysis. Only classroom numbers 15 and 19 were significantly associated with gender, indicating less female students than male students in classroom numbers 15 [Pearson $\chi^{2}=4.68, \mathrm{df}=1$, $P<.05 ;$ Phi $=0.105]$ and $19\left[\right.$ Pearson $\chi^{2}=4.49, \mathrm{df}=1$, $P<.05 ; \mathrm{Phi}=0.103]$. These results suggest that females' higher chance of belonging to the "Low Quality Pattern" was not consistently caused by attending the classrooms with a high percentage of students who perceived low quality in the sample.

\subsection{Mean Differences across the Latent Classes: Motivational Learning Outcomes. Similar to an analysis of covariance (ANCOVA), we tested for mean differences across the latent classes controlling for the covariates gender and age. Thus, we modeled a latent class analysis including the observed variables self-concept and interest as distal outcomes and adding gender and age as covariates to the LCA model to see how class membership predicts the distal outcome when controlling for the influence of covariates on the distal outcome [65]. Further, using the "Model Test" command of Mplus, the statistical significance of mean differences of self- concept and interest was tested with Wald chi-square tests of parameter equalities by describing equality of means as}


TABLE 2: Class-specific means and standard errors of motivational and cognitive learning outcomes.

\begin{tabular}{lcccccccc}
\hline & \multicolumn{2}{c}{ C1: High quality } & \multicolumn{2}{c}{ C2: High structuredness } & \multicolumn{2}{c}{ C3: High teacher support } & \multicolumn{2}{c}{ C4: Low quality } \\
& $M$ & SE & $M$ & SE & SE & S & M \\
\hline Self-concept & 3.24 & 0.15 & 3.05 & 0.16 & 2.95 & 0.12 & 2.63 \\
Interest & 3.86 & 0.13 & 3.42 & 0.12 & 3.32 & 0.18 & 3.03 \\
\hline
\end{tabular}

restrictions on the analysis model for the Wald test [60]. The class-specific means and standard errors of the distal outcomes self-concept and interest in mathematics classes are reported in Table 2 .

5.4.1. Self-Concept in Mathematics Class. Results revealed that students who had a high probability of belonging to Class 1 ("High Quality Pattern"; $M=3.24, \mathrm{SE}=0.13$ ) reported significantly higher self-concepts than students with a high probability of belonging to Class 4 ("Low Quality Pattern"; $M=2.63$, $\mathrm{SE}=0.08$; $\mathrm{C} 1$ versus $\mathrm{C} 4$ : Wald test $=$ 15.33 , $\mathrm{df}=1$, and $P>.01$ ). However, students with a high probability of belonging to Class 4 ("Low Quality Pattern"; $M=2.63, \mathrm{SE}=.083)$ reported significantly lower selfconcepts in mathematics class than students in any other subgroup $(\mathrm{C} 1$ versus $\mathrm{C} 4$ : Wald test $=15.33$, $\mathrm{df}=1$, and $P<.001$; C2 versus C4: Wald test $=7.56, \mathrm{df}=1$, and $P<.01$; C3 versus C4: Wald test $=3.84, \mathrm{df}=1$, and $P<.05$ ).

5.4.2. Interest in Mathematics Class. Results revealed that students who had a high probability of belonging to Class 1 ("High Quality Pattern"; $M=3.85, \mathrm{SE}=.119$ ) reported significantly higher values of interest in mathematics class than students in any other subgroup $(\mathrm{C} 1$ versus $\mathrm{C} 2$ : Wald test $=$ 6.57, $\mathrm{df}=1$, and $P=.01 ; \mathrm{C} 1$ versus $\mathrm{C} 3$ : Wald test $=4.73$, $\mathrm{df}=1$, and $P<.05 ; \mathrm{C} 1$ versus C4: Wald test $=30.24$, $\mathrm{df}=1$, and $P<.001)$. Inversely, students who had a high probability of belonging to Class 4 ("Low Quality Pattern"; $M=3.85, \mathrm{SE}=.119)$ reported significantly lower values of interest in mathematics class than students with a high probability of belonging to the "High Quality" (Class 1) subgroup and students with a high probability of belonging to the "High Structuredness" (Class 2) subgroup (C4 versus $\mathrm{C} 1$ : Wald test $=30.24, \mathrm{df}=1$, and $P<.001$; C4 versus C2: Wald test $=6.78, \mathrm{df}=1$, and $P<.01$ ).

5.4.3. Summary of Mean Differences across Classes. The results demonstrated that students with a high probability of belonging to the "High Quality Pattern" (Class 1) showed significantly higher interests than students from any other subgroup, while students' with a high probability of belonging to the "Low Quality Pattern" (Class 4) showed significantly lower self-concepts than students from any other subgroup.

\section{Discussion}

The aim of the present study was to explore how characteristics of classroom instruction relate to male and female students' attitudinal and affective learning characteristics in mathematics. To probe this question, our investigation focused on students' patterns of perceived instructional quality in secondary school mathematics classes and their role for students' self-concept and interest in math. Results of LCA analyses indicated the existence of four distinct student patterns and, thus, suggested that students' perception of the instructional quality in their classrooms is highly individualized and heterogeneous. Almost half of the students in the sample (about 46\%) belonged to a "challenging pattern" perceiving an overall low quality of instruction (low structuredness of content, low social support by the teacher, and low discursive effectiveness). These students also demonstrated lower levels of mathematics self-concept than students from any other subtype. Only a small percentage of students in the sample (about 10\%) belonged to a group of students who perceived high quality of instruction and also demonstrated significantly higher levels of mathematics self-concept and interest than students with other patterns of perceived instructional quality. Thus, results suggest that the impact of learning environments on students' learning outcomes depends highly on students' subjective experiences of their learning environments. The existence of distinct patterns of students' perceived instructional quality and their relations to students' mathematics self-concept and interest support the theoretical assumption that learning environments are shaped by the involved actors and their perceptions of the learning context [66]. Thus, our results suggested that learning success relates to these individually different perceptions. Accordingly, results of the present study suggest in line with previous research [25] that learning environments are processed in different ways by each student based on demographic characteristics. When examining demographic characteristics such as gender and age, which are associated with students' perception of their learning environment, results revealed that gender related significantly to students' perceived quality of instruction in mathematics. Age did not relate to students' patterns of perceived instructional quality.

Concerning significant associations between single classrooms and students' group membership, five of the twentyone classrooms were significantly related to students' group membership. Two of these five classrooms were also significantly associated with students' gender suggesting that female students' higher probability of belonging to the "Low Quality Pattern" was not consistently due to the fact that female students in our sample had on average poorer teachers. Our data did not include more teacherrelated information; thus we did not explore particular teacher characteristics, which might be related to students' group membership. However, for future analyses, it will be interesting to use the subgroup-related classrooms for 
the study of micro learning environments and to analyze, for instance, characteristics of questions, tasks, and received feedback within these classrooms [49].

The unique value of the present study lies in the highlighting of the particularly high probability of female students to belong to a group of students who, in comparison to male students, were significantly more likely to perceive an overall low quality of instruction in mathematics classes. These results align with previous research, suggesting that female students perceive less supportive feedback by their mathematics teachers [67] and perceive low opportunities to participate in classroom discourse [20]. Students who belonged to this "Low Quality" pattern also reported particular low levels of self-concept in math, which is associated with negative attitudes and emotions concerning their mathematics classes. The findings thus point to the urgent necessity to examine the ways in which the instructional design of mathematics classrooms can be better adapted to more effectively meet the needs of female students.

6.1. Implications for Educational Practice. As the results of the present study indicate that students' perceptions of their learning environments are highly diverse, and that these different perceptions are associated with students' learning outcomes, the findings highlight the necessity of taking into account strategies of differentiated instruction in mathematics education. Differentiated instruction allows teachers to provide choices to the students concerning content, learning processes, and products by, for example, using varied resource materials, tasks, and texts or adapting curriculum to students' learning processes [68]. Specifying these general characteristics of differentiated instruction, the two extreme subtypes as well as the mixed subtypes found in the present study indicate that mathematics teachers should differentiate content, learning processes, and products by considering students' different levels of perceived structuredness, support, and discursive effectiveness. Concretely, these variances can be targeted through the implementation of practices such as diverse feedback strategies and offering differently structured learning materials.

To address students' perceptions of their learning environment effectively, teacher evaluation is highly important. The instruments used in this study might be appropriate evaluation tools for regular student surveys. However, for optimal teacher evaluation, other aspects of instructional quality which relate to achievement and motivation such as task complexity or level of mathematical argumentation should also be taken into account [34].

In the present study, it was shown that female students belong, compared to male students, significantly more often to the subtype of learners who perceive mathematics classes as (a) less structured with respect to the presentation of the discussed content, (b) less supportive concerning teachers' behavior, and (c) allowing low levels of participation in classroom discourse. Thus, gender-appropriate teaching in mathematics is needed to enhance female students' positive evaluation of their learning environment in math. According to the presented results and the current state of research, gender-sensitive teaching strategies include the following.

(a) To facilitate structuredness of presented content in math class by involving different learning styles for different students-research on gender differences in learning styles, for example, suggested that female students tend to be reading- and-writing-based learners [69].

(b) To provide gender-balanced social support by the teacher-it is, for example, well known that, compared to male students, female students receive more negative feedback from their teachers concerning their intellectual abilities [70].

(c) To foster experiences of discursive effectiveness in the classroom by facilitating classroom discussions. Classroom discussions in mathematics can be facilitated by talking about mathematical concepts and procedures, introducing various discourse formats such as extended group discussion and allowing students to talk about their thinking and problem solving [71]. Another important point is to encourage female and male students equally to participate actively in these discussions by, for example, in the classroom puzzle strategy [72]. Hänze and Berger [73], for example, revealed in their study on teaching settings in 12th grade physics classes that critical groups with a low-academic self-concept such as female students felt clearly more competent in learning environments, which were characterized by cooperative instruction than in the traditional teaching setting.

6.2. Limitations. The design of the present study is crosssectional, and subsequently, the direction of relationships among the variables cannot be determined. Results do not indicate whether students' learning outcomes or other relevant factors impact the pattern of perceived instructional quality to which they belong or vice versa. As suggested by previous longitudinal analyses $[10,16]$, it was assumed that attitudinal and affective learning characteristics differ depending on students' perceived instructional quality. However, longitudinal studies are needed to conclusively determine the direction of influence. Second, the measurement instruments utilized depict only some aspects of the highly complex construct of instructional quality in mathematics. Further research is needed including additional characteristics of instructional quality, which are related to students' self-concept and interest in math such as challenge, sense of task novelty, or the opportunity to engage with others [9].

6.3. Conclusions. The present study highlights the necessity of instruction in mathematics classes to take into account learners' different ways of perceiving and evaluating their learning environment. Considering almost half of the sample in the present study had a high probability of perceiving low structuredness, low support, and low discursive effectiveness in their math classes and thus, particular low mathematical 
self-concept and interest, this research emphasizes that attitudes and emotions toward mathematics should be enhanced through increased adaption of mathematics classroom instruction to students' different learning strategies and by considering students expectations and perceptions of instructional quality in classroom discussions.

\section{Acknowledgments}

This research was supported by the European Social Fund (ESF) through the Research Programme on Advanced Training on Universities. The authors would like to thank the teachers and students for their participation in this paper.

\section{References}

[1] Kultusministerkonferenz, Strengthening Education in Math and Science-Recommendation of the Standing Conference of the Ministers of Education and Cultural Affairs of the Laender in the Federal Republic of Germany, http://www.kmk.org /fileadmin/veroeffentlichungen_beschluesse/2009/2009_05_07 -Empf-MINT.pdf, 2009.

[2] K. Neumann, H. E. Fischer, and A. Kauertz, "From pisa to educational standards: the impact of large-scale assessments on science education in Germany," International Journal of Science and Mathematics Education, vol. 8, no. 3, pp. 545-563, 2010.

[3] K. Singh, M. Granville, and S. Dika, "Mathematics and science achievement: effects of motivation, interest, and academic engagement," Journal of Educational Research, vol. 95, no. 6, pp. 323-332, 2002.

[4] H. W. Marsh and R. Shavelson, "Self-concept: its multifaceted hierarchical structure," Educational Psychologist, vol. 20, no. 3, pp. 107-133, 1985.

[5] H. W. Marsh and L. F. Scalas, "Self-concept in learning: reciprocal effects model between academic self-concept and academic achievement," in Social and Emotional Aspects of Learning, S. Järvelä, Ed., pp. 191-198, 2011.

[6] G. Nagy, U. Trautwein, J. Baumert, O. Köller, and J. Garrett, "Gender and course selection in upper secondary education: effects of academic self-concept and intrinsic value," Educational Research and Evaluation, vol. 12, no. 4, pp. 323-345, 2006.

[7] OECD (Organization for Economic Co-operation Development), PISA, 2006: Science CompetencieS For Tomorrow's World, OECD (Organization for Economic Co-operation and Development), Paris, France, 2007.

[8] U. Schiefele, A. Krapp, and A. Winteler, "Interest as a predictor of academic achievement: a meta-analysis of research," in The Role of Interest In learnIng and Development, K. A. Renninger, S. Hidi, and A. Krapp, Eds., pp. 183-1212, Erlbaum, Hillsdale, NJ, USA, 1992.

[9] K. A. Renninger and S. Hidi, "Revisiting the conceptualization, measurement, and generation of interest," Educational Psychologist, vol. 46, no. 3, pp. 168-184, 2011.

[10] A. C. Frenzel, T. Goetz, R. Pekrun, and H. M. G. Watt, "Development of mathematics interest in adolescence: influences of gender, family, and school context," Journal of Research on Adolescence, vol. 20, no. 2, pp. 507-537, 2010.

[11] H.-Y. Chen, M. S. Thompson, J. D. Kromrey, and G. H. Chang, "Relations of student perceptions of teacher oral feedback with teacher expectancies and student self-concept," The Journal of Experimental Education, vol. 79, no. 4, pp. 452-477, 2011.

[12] M. Waldis, U. Grob, C. Pauli, and K. Reusser, "The influence of instructional design on domain-specific interest and achievement in mathematics," in Design of Instruction And Instructional Quality-Results of An International germAn-Swiss Video Study on Mathematics Classes, K. Reusser, C. Pauli, and M. Waldis, Eds., pp. 209-251, Waxmann, Muenster, Germany, 2010.

[13] K. R. Wentzel, A. Battle, S. L. Russell, and L. B. Looney, "Social supports from teachers and peers as predictors of academic and social motivation," Contemporary Educational Psychology, vol. 35, no. 3, pp. 193-202, 2010.

[14] M. K. Demaray, C. K. Malecki, S. Y. Rueger, S. E. Brown, and K. H. Summers, "The role of youth's ratings of the importance of socially supportive behaviors in the relationship between social support and self-concept," Journal of Youth and Adolescence, vol. 38, no. 1, pp. 13-28, 2009.

[15] C. Pauli and F. Lipowsky, "Participating or listening? Students' verbal contributions in mathematics classes," Unterrichtswissenschaft, vol. 35, no. 2, pp. 101-124, 2007.

[16] Z. Daniels, Developing Schoolbased Interests in Adolescence, Waxmann, Muenster, Germany, 2008.

[17] F. Lipowsky, K. Rakoczy, C. Pauli, B. Drollinger-Vetter, E. Klieme, and K. Reusser, "Quality of geometry instruction and its short-term impact on students' understanding of the Pythagorean Theorem," Learning and Instruction, vol. 19, no. 6, pp. 527-537, 2009.

[18] J. Brophy, Teaching. Educational Practices Series 1, International Academy of Education, International Bureau of Education, PCL, Lausanne Switzerland, International Academy of Education, Brussels, Belgium, 2000.

[19] H. Ditton, "Students' perspective on teachers and classrooms: results of a study on mathematics education," ZeitschRiFt FüR Pädagogik, vol. 48, no. 2, pp. 262-286, 2002.

[20] J. S. Eccles, C. Midgley, A. Wigfield et al., "Development during adolescence: the impact of stage-environment fit on young adolescents' experiences in schools and in families," American Psychologist, vol. 48, no. 2, pp. 90-101, 1993.

[21] D. H. Schunk and F. Pajares, "Self-efficacy theory," in Handbook of Motivation at School, K. R. Wentzel and A. Wigfield, Eds., pp. 35-53, Routledge, New York, NY, USA, 2009.

[22] J. G. Greeno, A. M. Collins, and L. B. Resnick, "Cognition and learningin," in Handbook of Educational Psychology, D. C. Berliner and R. C. Calfee, Eds., pp. 15-46, Macmillan, New York, NY, USA, 1996.

[23] C. P. Niemiec and R. M. Ryan, "Autonomy, competence, and relatedness in the classroom: applying self-determination theory to educational practice," Theory and Research in Education, vol. 7, no. 2, pp. 133-144, 2009.

[24] P. Cobb and J. Bowers, "Cognitive and situated learning perspectives in theory and practice," Educational Researcher, vol. 28, no. 2, pp. 4-15, 1999.

[25] A. Helmke, Instructional Quality and Teacher Professionality: Diagnosis, Evaluation, and Enhancement of Instruction, Kallmeyer, Seelze-Velber, Germany, 2009.

[26] E. L. Deci and R. M. Ryan, Handbook of Self-Determination Research, University of Rochester Press, New York, NY, USA, 2002.

[27] E. Sierens, M. Vansteenkiste, L. Goossens, B. Soenens, and F. Dochy, "The synergistic relationship of perceived autonomy 
support and structure in the prediction of self-regulated learning," British Journal of Educational Psychology, vol. 79, no. 1, pp. 57-68, 2009.

[28] H. Valås and N. Søvik, "Variables affecting students' intrinsic motivation for school mathematics: two empirical studies based on Deci and Ryan's theory on motivation," Learning and Instruction, vol. 3, no. 4, pp. 281-298, 1994.

[29] A. C. Frenzel, R. Pekrun, and T. Goetz, "Perceived learning environment and students' emotional experiences: a multilevel analysis of mathematics classrooms," Learning and Instruction, vol. 17, no. 5, pp. 478-493, 2007.

[30] M. Kunter, J. Baumert, and O. Köller, "Effective classroom management and the development of subject-related interest," Learning and Instruction, vol. 17, no. 5, pp. 494-509, 2007.

[31] O. Lüdtke, A. Robitzsch, U. Trautwein, and M. Kunter, "Assessing the impact of learning environments: how to use student ratings of classroom or school characteristics in multilevel modeling," Contemporary Educational Psychology, vol. 34, no. 2, pp. 120-131, 2009.

[32] M. Clausen, Instructional Quality: A Matter of Perspective? Waxmann, Münster, Germany, 2002.

[33] M. Croon, "Ordering the classes," in Applied Latent Class Analysis, J. A. Hargenaas and A. L. McCutcheon, Eds., pp. 137212, Cambridge University Press, New York, NY, USA, 2002.

[34] E. Klieme, F. Lipowsky, K. Rakoczy, and N. Ratzka, "Quality dimensions and effectiveness of mathematics instruction. Theoretical background and selectedfindings of the Pythagoras project," in Research on Educational Quality of Schools. FInal Report of the DFG Priority Program, M. Prenzel and L. Allolio-Naecke, Eds., pp. 127-146, Waxmann, Muenster, Germany, 2006.

[35] E. Klieme, G. Schuemer, and S. Knoll, "Mathematics instruction at secondary level. Task culture and instructional design," in TIMSS-Impulse für Schule und Unterricht. Forschungsbefunde, Reforminitiativen, Praxisberichte und Video-Dokumente, Bundesministerium für Bildung und Forschung (BMBF), Ed., pp. 43-57, Medienhaus Biering, Munich, Germany, 2001.

[36] J. Baumert, M. Kunter, W. Blum et al., “Teachers' mathematical knowledge, cognitive activation in the classroom, and student progress," American Educational Research Journal, vol. 47, no. 1, pp. 133-180, 2010.

[37] M. C. Wang, G. D. Haertel, and H. J. Walberg, "Toward a knowledge base for school learning," Review of Educational Research, vol. 63, no. 3, pp. 249-294, 1993.

[38] S. Gruehn, Teaching and Learning in School: Students As Sources of Lesson Descriptions, Waxmann, Muenster, Germany, 2000.

[39] N. Ntoumanis, "A self-determination approach to the understanding of motivation in physical education," British Journal of Educational Psychology, vol. 71, no. 2, pp. 225-242, 2001.

[40] L. Festinger, "A theory of social comparison processes," Human Relations, vol. 7, no. 2, pp. 117-140, 1954.

[41] J. V. Wood, "Theory and research concerning social comparisons of personal attributes," Psychological Bulletin, vol. 106, no. 2, pp. 231-248, 1989.

[42] C. P. H. Langford, J. Bowsher, J. P. Maloney, and P. P. Lillis, "Social support: a conceptual analysis," Journal of Advanced Nursing, vol. 25, no. 1, pp. 95-100, 1997.

[43] B. R. Sarason, G. R. Pierce, E. N. Shearin, I. G. Sarason, J. A. Waltz, and L. Poppe, "Perceived social support and working models of self and actual others," Journal of Personality and Social Psychology, vol. 60, no. 2, pp. 273-287, 1991.
[44] M. Reinboth, J. L. Duda, and N. Ntoumanis, "Dimensions of coaching behavior, need satisfaction, and the psychological and physical welfare of young athletes," Motivation and Emotion, vol. 28, no. 3, pp. 297-313, 2004.

[45] M. Walshaw and G. Anthony, “The teacher's role in classroom discourse: a review of recent research into mathematics classrooms," Review of Educational Research, vol. 78, no. 3, pp. 516-551, 2008.

[46] D. Sembill and K. Gut-Sembill, "Questions behind students' questions-to inquire students' questions in class," Unterrichtswissenschaft, vol. 32, no. 4, pp. 321-333, 2004.

[47] R. Lazarides and A. Ittel, "Classroom characteristics, mathematics self-concept and interest," in Differentiation in Math and Science Classes. Implications For Theory and Educational Practice, R. Lazarides and A. Ittel, Eds., Klinkhardt, Bad Heilbrunn, Germany, 2012.

[48] H. W. Marsh, "Age and sex effects in multiple dimensions of self-concept: preadolescence to early adulthood," Journal of Educational Psychology, vol. 81, no. 3, pp. 417-430, 1989.

[49] T. Seidel, "The role of student characteristics in studying micro teaching-learning environments," Learning Environments Research, vol. 9, no. 3, pp. 253-271, 2006.

[50] A. Helmke, Assessing, Evaluating, and Enhancing Instructional Quality, Kallmeyer, Seelze, Germany, 2003.

[51] E. Sierens, M. Vansteenkiste, L. Goossens, B. Soenens, and F. Dochy, "The synergistic relationship of perceived autonomy support and structure in the prediction of self-regulated learning," British Journal of Educational Psychology, vol. 79, no. 1, pp. 57-68, 2009.

[52] M. M. Mitchell, C. P. Bradshaw, and P. J. Leaf, "Student and teacher perceptions of school climate: a multilevel exploration of patterns of discrepancy," Journal of School Health, vol. 80, no. 6, pp. 271-279, 2010.

[53] G. Nagy, H. M. G. Watt, J. S. Eccles, U. Trautwein, O. Lüdtke, and J. Baumert, "The development of students' mathematics self-concept in relation to gender: different countries, different trajectories?" Journal of Research on Adolescence, vol. 20, no. 2, pp. 482-506, 2010.

[54] L. Hoffmann, A. Krapp, A. K. Renninger, and J. Baumert, Eds., Interest and Learning: Proceedings of the Seeon Conference on Interest and Gender, IPN, Kiel, Germany, 1998.

[55] J. E. Jacobs, S. Lanza, D. W. Osgood, J. S. Eccles, and A. Wigfield, "Changes in children's self-competence and values: gender and domain differences across grades one through twelve," Child Development, vol. 73, no. 2, pp. 509-527, 2002.

[56] K. Neumann, A. Kauertz, and H. E. Fischer, "Quality of instruction in science education," in Second International Handbook of Science Education, B. J. Fraser, K. Tobin, and C. McRobbie, Eds., vol. 1, pp. 247-258, Springer, Dordrecht, Germany, 2012.

[57] B. Steinert, M. Gerecht, E. Klieme, and P. Döbrich, School Quality Measures: Documentation of the Survey Instruments For the APU and PEB, GFPF ua, Frankfurt a. M., Germany, 2003.

[58] R. Berger, "Influence of context-based physics class on interest and performance in upper secondary school," Zeitschrift für Didaktik der Naturwissenschaften, vol. 8, no. 1, pp. 119-132, 2002.

[59] W. Bos, E. M. Lankes, M. Prenzel et al., IGLU: Documentation of the Survey Instruments, Waxmann, Muenster, Germany, 2006.

[60] B. O. Muthén and A. Satorra, “Technical aspects of Muthén's liscomp approach to estimation of latent variable relations 
with a comprehensive measurement model," Psychometrika, vol. 60 , no. 4, pp. 489-503, 1995.

[61] H. Akaike, "A new look at the statistical model identification," IEEE Transactions on Automatic Control, vol. 19, no. 6, pp. 716-723, 1974.

[62] G. Schwartz, "Estimating the dimension of a model," Annals of Statistics, vol. 6, no. 2, pp. 461-464, 1978.

[63] J. Rost, "Latent-class analyses," in Handbook of Psychological Diagnostics, F. Petermann and M. Eid, Eds., pp. 275-287, Hogrefe, Goettingen, Germany, 2006.

[64] K. L. Nylund, T. Asparouhov, and B. O. Muthén, "Deciding on the number of classes in latent class analysis and growth mixture modeling: a Monte Carlo simulation study," Structural Equation Modeling, vol. 14, no. 4, pp. 535-569, 2007.

[65] S. L. Clark and B. O. Muthén, "Relating latent class analysis results to variables not included in the analysis," In press.

[66] K.-O. Bauer, "Models of instructional quality," in Instructional Quality and Subject-Didactic Research. Models and Measures of Domain-Specific Learning Conditions and Competences, $\mathrm{K}$. O. Bauer and N. Logemann, Eds., pp. 51-74, Waxmann, Muenster, Germany, 2011.

[67] J. S. Eccles, “Gender roles and women's achievement-related decisions," Psychology of Women Quarterly, vol. 11, no. 2, pp. 135-172, 1987.

[68] J. A. Bianchini and M. E. Brenner, "The role of induction in learning to teach toward equity: a study of beginning science and mathematics teachers," Science Education, vol. 94, no. 1, pp. 164-195, 2010.

[69] E. A. Geist and M. King, "Different, not better: gender differences in mathematics learning and achievement," Journal of Instructional Psychology, vol. 35, no. 1, pp. 43-52, 2008.

[70] E. R. Altermatt, "Coping with academic failure: gender differences in students' self-reported interactions with family members and friends," Journal of Early Adolescence, vol. 27, no. 4, pp. 479-508, 2007.

[71] S. H. Chapin, C. O. 'Connor, and N. C. Anderson, Classroom Discussions: Using Math Talk To Help Students Learn, Grades K-6, Math Solutions Publications, Sausalito, CA, USA, 2003.

[72] E. Aronson, "Building empathy, compassion, and achievement in the jigsaw classroom," in Improving Academic Achievement. Impact of Psychological Factors on Education, J. Aronson, Ed., pp. 209-225, Academic Press, San Diego, Calif, USA, 2002.

[73] M. Hänze and R. Berger, "Cooperative learning, motivational effects, and student characteristics: an experimental study comparing cooperative learning and direct instruction in 12th grade physics classes," Learning and Instruction, vol. 17, no. 1, pp. 29-41, 2007. 


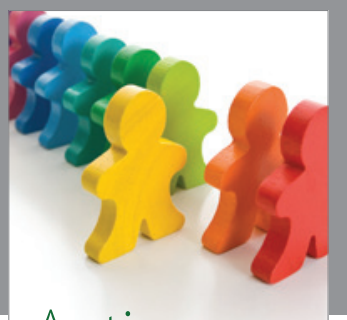

Autism

Research and Treatment
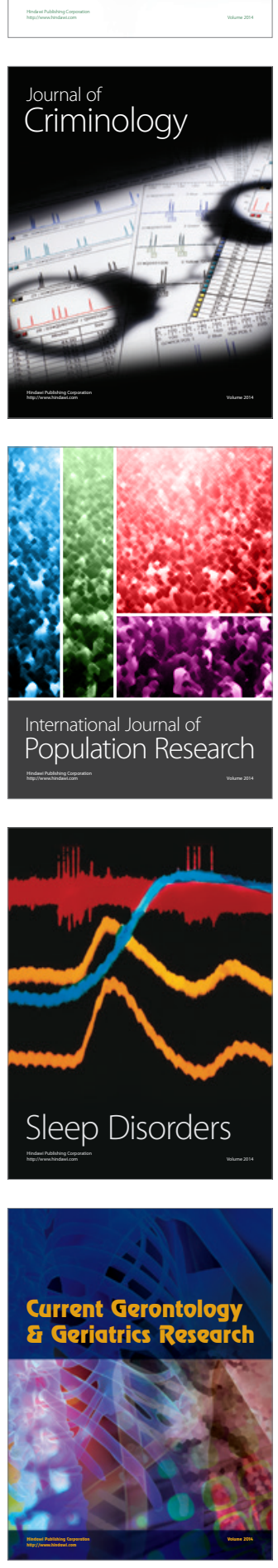
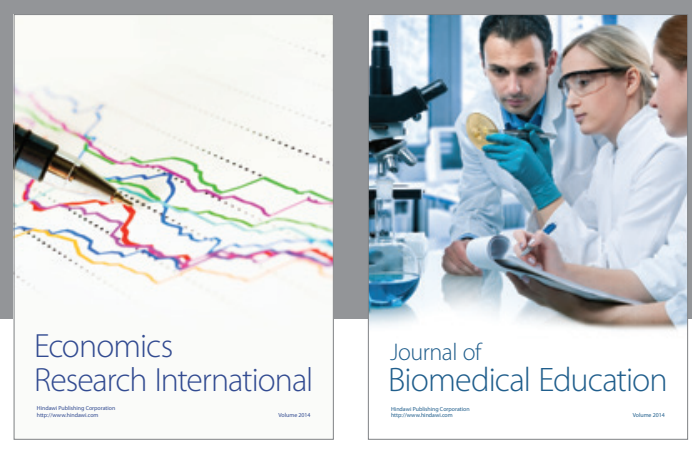

Journal of

Biomedical Education

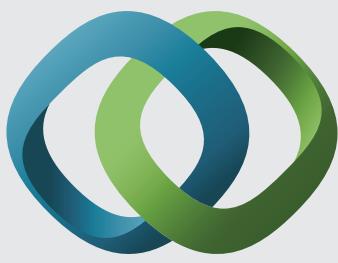

\section{Hindawi}

Submit your manuscripts at

http://www.hindawi.com
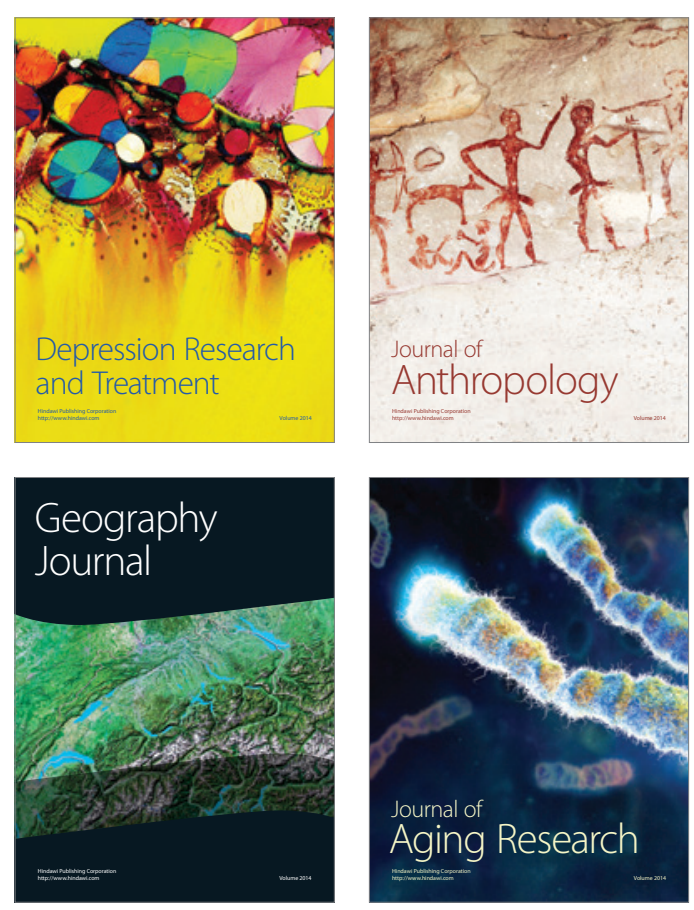

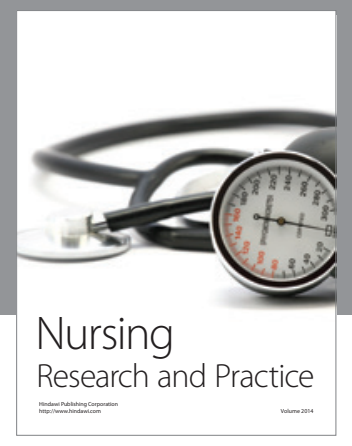

Nursing

Research and Practice

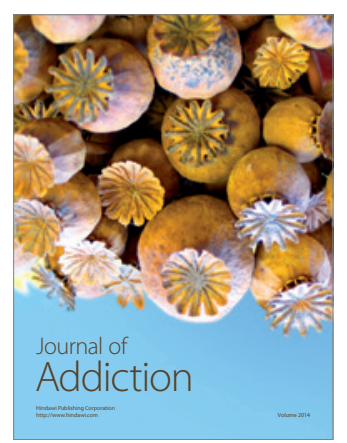

Child Development

Research

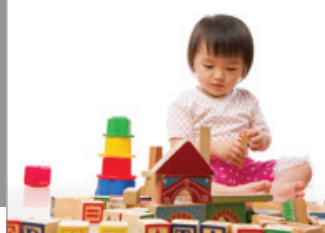

迥
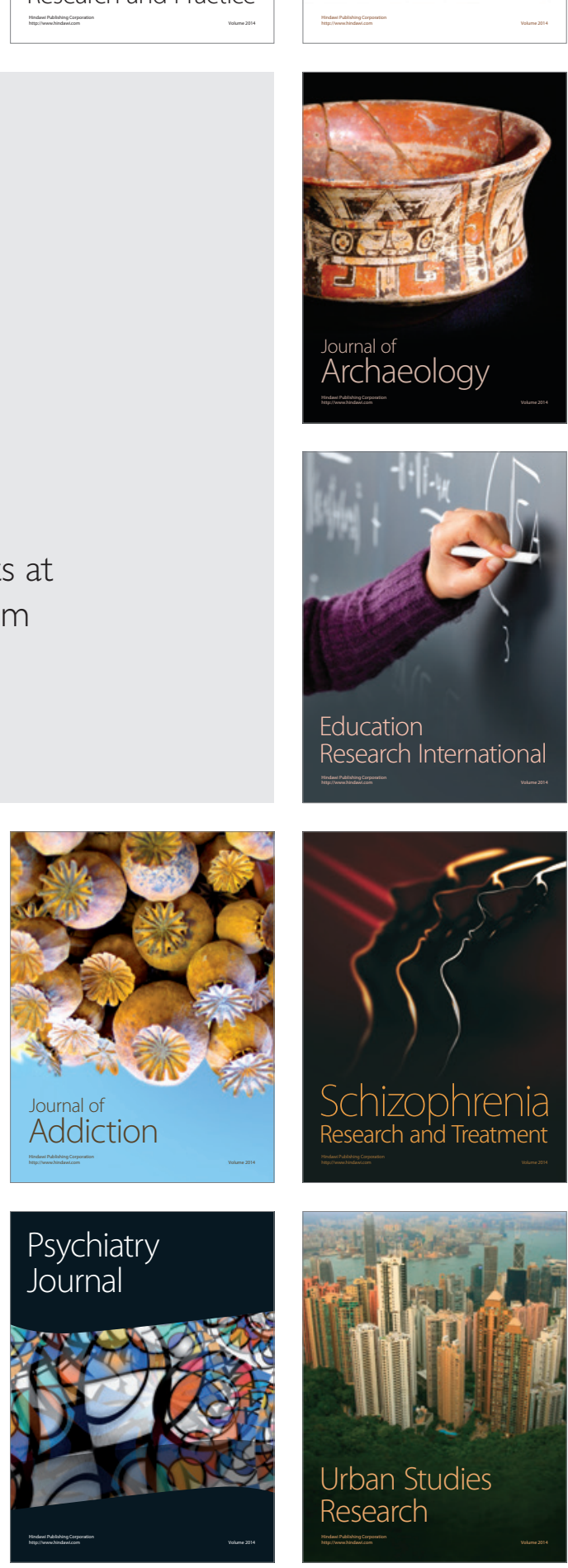